\title{
Discrete Choice Experiments in Developing Countries: Willingness to Pay Versus Willingness to Work
}

\author{
J. M. Gibson ${ }^{3}$ - D. Rigby ${ }^{1}$ - D. A. Polya ${ }^{2}$ - N. Russell ${ }^{1}$
}

Accepted: 15 April 2015 / Published online: 9 May 2015

(C) The Author(s) 2015. This article is published with open access at Springerlink.com

\begin{abstract}
A concern when conducting stated preference valuation studies in rural developing or very low income contexts is the use of monetary willingness to pay (WTP) estimates. In circumstances where cash incomes are extremely low, a significant proportion of the population are not engaged in waged labour and the exchange of goods or services is augmented through barter or work exchange, the role of money is likely to be different from that within an urban developed setting. As such, ability to pay using money may be impaired and downwardly biased when compared with other mediums of exchange. In recognition of this several studies have used hypothetical labour contributions as payment vehicles and a common finding is that households are more often willing to contribute labour than they are money. In this paper we present the results of a split sample DCE using money and labour contributions as payment vehicles for improved drinking water quality in Kandal Province, Cambodia. We find little differences between the payment vehicles in terms of attribute non-attendance, marginal utilities of attributes or derived welfare values. We argue that this provides support for the use of WTP in rural developing areas where there are functioning labour markets.
\end{abstract}

Keywords Choice experiments - Development - Health - Payment vehicles - WTP . WTW $\cdot$ Risk - Water $\cdot$ Latent class $\cdot$ Attribute non-attedance

\section{Introduction}

The valuation of environmental stocks and services is increasingly undertaken in developing countries. Elicitation and estimation of willingness to pay (WTP) in such contexts poses many

This paper has not been submitted elsewhere in identical or similar form, nor will it be during the first three months after its submission to the publisher.

$\triangle$ J. M. Gibson

jon.m.gibson@manchester.ac.uk

1 Economics, School of Social Sciences, University of Manchester, Manchester, UK

2 School of Earth, Atmospheric and Environmental Sciences, University of Manchester, Manchester, UK

3 Manchester Centre for Health Economics, University of Manchester, Manchester, UK 
challenges ranging from lack of detailed data for revealed preference studies to language, cultural and logistical barriers for stated preference studies. The challenges are such that the validity of some stated preferences studies in developing countries has been called into question (Whittington 2002).

One significant concern highlighted in the literature (see for instance Hardner 1996; Hung et al. 2007; Casiwan-Launio et al. 2011) is the use of monetary WTP measures with the rural poor. Since cash incomes are extremely low, a significant proportion of the population are not engaged in waged labour and the exchange of goods or services is augmented through barter or work exchange, the role of money income in the rural developing setting is likely to be different from that of an urban developed setting.

It has been argued that, in these contexts, WTP measures, based on ability to pay using money, will not appropriately represent the economic value of the policy/good/attribute under consideration, given that economic exchanges may occur without the use of money (see for instance Hardner 1996; Hung et al. 2007; Casiwan-Launio et al. 2011). Furthermore, since this downward bias would particularly affect the WTP estimates of the rural poor, those households who are perhaps most in need of assistance may be unduly discriminated against in wider project analysis that utilises WTP estimates. The problem may be further amplified through increased hypothetical biases. Given that rural poor households may not be as integrated with markets compared with households in developed countries, hypothetical contingent markets, which are key for stated preference surveys, may seem less realistic which could lead to unreliable results.

Fundamental to this issue is a lack of markets using money as the medium of exchange, the predominant reason why non-market valuation studies are undertaken in the first place. Access to labour, goods and credit markets would permit a household to liquidate current assets to allocate resources efficiently or to access credit for increased current consumption. In these circumstances WTP estimates based on payments using money would be an appropriate welfare measure. In rural developing country settings barter and work exchange can facilitate exchanges in lieu of fully functioning monetary markets. ${ }^{1}$

If a household does not have the ability to utilise markets to access money, response to stated preference survey questions, which often specifically ask households to consider their money income before responding to stated preference questions, will be made in relation to these liquidity constraints and may thus provide a biased estimate of true economic value. It may therefore be pertinent to consider trade-offs with respect to other resources, rather than, or in addition to, money.

Researchers have used a variety of alternative payment vehicles in stated preference valuation studies, for instance Shyamsundar and Kramer (1996) use baskets of rice and Asquith et al. (2008) used in-kind payments such as beehives. However, the most common substitute for money in stated preference studies is labour contributions (Hardner 1996; Kamuanga et al. 2001; O'Garra 2009; Casiwan-Launio et al. 2011; Rai and Scarborough 2013, 2014).

Labour is the most commonly used alternative to money due both to the ubiquitous nature of potential working hours, i.e. all households are faced with the decision of how best to allocate their time between productive and leisure activities, and because labour time is arguably the most important asset at the disposal of the rural household.

The utilisation of household time for productive activities, however, may be limited by the available labour market or self-employment opportunities, potentially leading to an unsatisfied demand for work and constrained money income. Although utilising these available

1 However transaction costs are likely to be high in terms of matching buyers and sellers which may lead to inefficiencies. 
working hours, rather than constrained money income, as a medium of exchange in stated preference studies might ease the problem of downwardly biased WTP measures, using working time as a payment vehicle for assessing welfare effects is potentially complicated by the need to apply an opportunity cost of time to achieve monetary measures of welfare and the uncertain impact that the choice of payment vehicle may have on choice behaviour.

Further complications occur due to the fact that the nature of work task involved, for example the laboriousness of the task, will likely have an effect on the decision of the household or individual to accept the offer (Ahlheim et al. 2010), thus different studies using different labour tasks would likely lead to different welfare valuations.

A major concern with using labour time as a utility measure is that the value of time is highly dependent on the opportunity cost of that time. For instance during the crop-harvesting period for rural households, time is likely to be at a premium whereas in other periods time is likely to be relatively cheap. Unlike money, time cannot be saved during plentiful periods to smooth consumption. Further, those individuals who are in full time work may be heavily time constrained but relatively well off in terms money income. Using either payment vehicle would lead to potential issues depending on the work and income levels of the individual respondent.

Given the potential issues related to using labour contributions as a payment vehicle in stated preference valuation studies, recent empirical studies have focused on several themes including: how do the size of welfare measures, derived using the different payment vehicles, compare and how might a welfare measure, expressed in labour hours, be monetised for use in cost-benefit analysis. What has not received much attention, however, is how the payment vehicle affects choice behaviour in SP tasks, in terms of protest votes and attribute nonattendance (ANA). It is these points that we address in this paper.

As noted by Vondolia et al. (2014) a common finding from CV studies which utilise the labour payment vehicle in rural areas of developing countries is that there is a higher rate of acceptance for the scenario, i.e. they provide a positive WTP. The use of a labour payment vehicle is conceivably seen as a more realistic scenario within these contexts and thus the use of labour payment vehicles could reduce protest votes and increase the acceptance of the survey.

In a choice experiment setting protests or low acceptance due to the payment vehicle could be channeled in several ways: (i) they could ignore the payment attribute, regardless of the level, when making their selection from the choice set (i.e. not attend the price attribute), (ii) they could respond by using a heuristic such as choosing the lowest priced alternative, (iii) they could choose randomly, (iv) they could refuse to participate in, or drop out of, the choice experiment or (v) the respondents could consistently choose the status-quo option.

However, in the choice experiment presented here there was no status-quo option which rules out protest route (v). This leaves alternatives (i)-(iv) as methods to protest the payment vehicle or display a lack of acceptance in the discrete choice experiment.

In light of the increased use of labour contributions as a medium of exchange in stated preference studies and the potential deficiencies of money-based WTP measures in low income contexts, the research presented here examines the differences between rural households' willingness to contribute labour and households' willingness to contribute money for water source improvements in order to examine the validity of money-based WTP estimates in rural developing areas.

In this study we also examine the suitability and acceptability of the work and money payment vehicles through examination of the marginal utility parameters in the estimated choice models to identify whether alternatives (ii) and (iii) were utilised and we estimate parameter constrained latent class choice models to examine the degree of attribute non- 
attendance towards the two payment vehicles (i). This allows us to use the estimated models to comment on the degree of acceptance of the two payment vehicles.

This paper presents the results of a split sample discrete choice experiment in Kandal province, Cambodia, where households have been informed of the results of geochemical surveys of arsenic content in their drinking water. Half of the respondents are asked about improved drinking water sources in relation to using money as a payment (MAP) with the other half asked in relation to using work as a payment (WAP) method. We investigate (a) the implicit value of time and draw comparisons to local market wage rates, (b) attribute non-attendance stability between payment vehicles through estimation of latent class choice models, and (c) parameter stability between the samples through estimation of a pooled heteroscedastic conditional logit model.

The structure of the paper is as follows: Sect. 2 presents a review of previous WTW studies; Sect. 3 describes the arsenic problem on which the choice experiment focuses as well as the experimental design, sampling procedure and the data collection process; Sect. 4 presents the empirical results and Sect. 5 concludes with discussion.

\section{Related Literature}

\subsection{Contingent Valuation Studies}

Early applications of utilising labour as a payment vehicle were used within contingent valuation studies estimating welfare measures for common goods in highly non-monetised communities.

One early application of labour as a payment vehicle in a stated preference study is Hardner (1996) who conducted a contingent valuation (CV) exercise to study the economic benefits of potable water provision in rural Ecuador. The study area was a rural, subsistence agriculturebased community where many economic exchanges were non-monetised. In recognition of this the study used working hours towards construction of water treatment systems as a payment vehicle instead of money. Of their sample, $72 \%$ provided a positive willingness to work value which suggests that the respondents were receptive to forms of exchange other than money. Due to the extreme lack of markets or property rights in the area questions related to money were not asked and so a direct comparison of WTW and WTP was not possible.

In later studies researchers were able to ask respondents dual contribution questions, related to both labour time and money. For example, a trio of studies (Swallow and Woudyalew 1994; Echessah et al. 1997; Kamuanga et al. 2001) focusing on tsetse fly reduction in Africa implemented contingent valuation studies with both money and labour as numeraires, allowing comparison. Swallow and Woudyalew (1994), working in Ethiopia, conducted a CV study to examine the willingness to contribute labour and money towards theft prevention of tsetse fly reduction baits. The study found that more individuals were willing to contribute time rather than money although no attempt is made to compare the two measures directly.

The authors suggest that this might be due to high demands for cash and relatively constrained opportunities for generating income. The study finds that households headed by females and households headed by someone who works 'off farm' are willing to contribute less time than other households. They also find that households who have more cattle, as a proxy for wealth, are willing to contribute more of both labour and money.

Both Echessah et al. (1997) and Kamuanga et al. (2001) also find that a higher proportion of households were willing to contribute labour than money. Although the studies investigate 
the factors that influence willingness to contribute money and labour, a direct comparison in terms of economic value estimates provided by the two measures, through monetisation of labour contributions, is not made.

Hung et al. (2007) conduct a small scale CV study to examine willingness to supply labour or payments to develop firebreaks in order to limit forest fires in Vietnam. This study draws the same conclusion as the tsetse fly studies: that respondents were more willing to contribute labour than money. Only 7 out of 70 respondents were unwilling to contribute any time whereas 57 out of 70 respondents were unwilling to contribute money.

The contingent valuation studies discussed up to this point clearly illustrate the acceptability of labour contributions as a payment vehicle to respondents and that in these developing settings a proportion of households has been willing to give up time even when they have declined to contribute money. This suggests that valuation studies focused exclusively on WTP estimates using money as the medium of exchange would undervalue the economic benefits under investigation. These studies however do not make a direct comparison of WTP and WTW values through the monetisation of work time contributions, which would be required in order to utilise the benefit estimates for cost-benefit analysis.

A contingent valuation study which estimated monetary values of labour contributions is O'Garra (2009), who questioned respondents on their willingness to contribute time and money towards marine conservation in Fiji. The study estimates monetised welfare measures using two opportunity costs of time: a wage rate and a leisure rate. The leisure rate assumes that respondents would reallocate time currently being used for leisure, rather than work time, when allocating time in the contingent valuation question. As such, using a result accredited to Cesario (1976), one third of the wage rate was used as the opportunity cost of leisure time. This result was used to monetise labour contributions for comparison with direct WTP estimates.

The study finds that monetised WTW, using the leisure conversion rate, welfare estimates are not significantly different from direct WTP estimates using money. The use of the one third wage rate as the opportunity cost of time is a critical assumption for this result as using the full wage rate would clearly result in a higher monetised WTW estimate than the WTP estimate.

In researching the potential sustainability of marine protected areas in the Philippines, Casiwan-Launio et al. (2011) consider both money and labour hours as payment vehicles using a split-sample CV approach. They also utilise the assumption that the opportunity cost of time is one third the value of the wage rate. Wage data is thus used to monetise the WTW estimates for comparison with WTP and they find that WTW is between 3 and 8 times larger than WTP. They provide two potential explanations for this divergence.

Firstly that missing markets might decrease the opportunity cost of time. By not having access to a labour market with available demand to sell excess labour, or by having high transaction costs to access the market, households may have too much labour applied to self-employment, or leisure, than would otherwise be the case. This would lead to increased preferences for money, relative to labour, and could lead to the observed divergence between WTP and WTW. A second suggested hypothesis put forward by the authors is that the divergence is the result of an endowment effect. Commitment of money represents the fruits of previously applied labour whereas commitment of labour hours is the opportunity cost of potential future income derived from work not yet undertaken.

A further paper that makes use of the assumption that the opportunity cost of leisure is a third of the size of hourly wage rate is Arbiol et al. (2013). This paper utilised labour contributions to examine the economic value of human leptospirosis prevention in urban Manila. They find that respondents are receptive to using labour time to reduce human leptospirosis, 
even when the jobs involve activities potentially seen as unpleasant such as environmental clean-up activities to reduce rat populations. The authors attribute this acceptance rate to high levels of unemployment. The study did not simultaneously collect WTP with respect to money and so a direct comparison was not made.

Tilahun et al. (2013), examining forest conservation in Ethiopia, discuss the potential issues of using wage rates to value the opportunity cost of labour contributions. Firstly they point to imperfect labour markets in rural settings. There may be more households willing to contribute labour than there are willing to employ labour. As such the slack labour market may reduce the opportunity cost of time relative to the households' preference to supply labour. The households will therefore be less likely to consider market wages as a foregone opportunity when contemplating labour contributions in the valuation scenario. They further note that as in some rural contexts the households will spend little time working in employed labour and the majority of the time self-employed, the opportunity cost of time in slow agricultural seasons, such as after crops have been harvested, is likely to be zero. As such the study utilises per capita daily income of the respondent rather than market wage rates to compare monetised WTW estimates with WTP estimates and finds a $99 \%$ overlap in the confidence intervals of the two estimates.

Seemingly many of the problems associated with using money as a payment vehicles in these contexts is associated with the experience that the individual will have had with using money as means of exchanging goods or services. If a household has little experience with money, the hypothetical gap and limited access to money may lead to biases. Investigating this issue Vondolia et al. (2014) examines the influence of experience with using either money or labour as a means of payment on protest votes and mean willingness to pay. The study finds that experience with the payment vehicles reduces asymmetries in acceptance rates. This suggests that respondent experience should be carefully considered when selecting a payment vehicle for a stated preference valuation study for the rural poor in a developing country.

These CV studies focus on the valuation of a public good, for a local area, such as firebreaks, tsetse fly traps or conservation. As such, discernible labour contributions are perhaps an obvious way to sustain these communal goods where concerns such as free riding might impact the effectiveness of less visible monetary contributions. There has been little focus however on willingness to contribute labour in order to obtain a private or club good. In this paper we focus on demand for a good to which access is described as excludable but not explicitly as rivalrous.

\subsection{DCE Studies}

Abramson et al. (2011) conducted one of the first DCEs which uses WTW as a payment vehicle, as part of an examination of financing alternatives for improved water services which also included a repayable loan. The financing option was included as an attribute in the choice experiment which enables the estimation of an internal opportunity cost of time, as the ratios of WTP to WTW. The study finds that WTP using money is low compared with potential project costs although WTP significantly increases when using loans or labour contributions. In addition to cost recovery for beneficial development programs, this is also an important result for valuation studies in general. In cash constrained economies WTP using money may return a relatively low economic value compared with other payment vehicles.

In a further DCE which addressed the mode of payment, Rai and Scarborough (2013) included both labour and monetary contributions as attributes in a study of invasive plant species in Nepal. Having both attributes for each option in the choice set enabled the examination of individual time-money trade-offs, or shadow wage rates. The shadow wage rate 
estimated was found to be different from the local wage rates. This shadow wage rate or the shadow value of labour is an alternative to other studies which use local wages either in their entirety or weighted.

In a related study Rai and Scarborough (2014) report the findings of a similar DCE, however, on this occasion a split sample approach was used where the respondent was permitted to choose their preferred payment option, either money or labour, for the DCE. Roughly $35 \%$ chose the money option whilst the remainder $(65 \%)$ chose the labour option. In doing so the authors were able to examine the determinants of payment vehicle choice as well as comparing the WTP or implicit prices. Self-selection of the payment method by the respondent however diminishes the applicability of comparisons between welfare estimates from each payment vehicle, given that households who are relatively better educated and hold more land are observed to choose the monetary option more often. As such, in the study presented here we use a random assignment of respondents with half of the sample being assigned a choice task involving money as the payment vehicle and half being assigned a labour based choice task.

In summary the literature in this field, to date, addresses the concern that WTP using money potentially underestimates economic values. The central conclusion is that respondents express a greater willingness to contribute labour than cash in rural developing environments and in areas with high levels of unemployment. This poses serious questions for the use of WTP with money as payment vehicle in these settings. However further examination of the use of labour as an alternative payment vehicle is warranted within the DCE methodology given the relatively little attention paid to choice behaviour, choice consistency, protests or attribute non-attendance. In the research presented here we test for differences in marginal utilities, ANA and choice consistency, due to the choice of labour as a payment vehicle, by conducting a split sample DCE where respondents are randomly assigned to a DCE with either a labour or money payment vehicle.

\subsection{Labour, Markets and Shadow Wage Rates}

The literature on agricultural household models (AHMs) focuses on the role of markets in allowing separation of production and consumption decisions (Singh et al. 1986; Skoufias 1994; Taylor and Adelman 2003) and elucidates the potential effects of markets on rural agricultural household labour demand and supply. In a situation of complete markets a household's agricultural production decisions are separate from their labour supply decisions and appear only as a budget to fund consumption and leisure. In these circumstances and when households spend some time in market based work, the wage rate that they achieve represents the opportunity cost of their time. In these circumstances WTP would provide an unbiased estimate of economic value.

In circumstances where labour markets are missing household members may be constrained to farm or household work. Labour applied to the farm is thus dependent on household preferences for leisure and the amount of leisure taken is dependent on the technical capabilities of the farm. The preference for money will thus rise relative to leisure (time) for those households with limited access to labour markets. This lack of markets is a potential factor leading to the finding of higher willingness to contribute labour than money.

\section{Experimental Design and Data}

The choice experiment conducted here focuses on rural households' willingness to contribute either money or labour towards improved drinking water quality. The study was conducted 
in Kandal province, Cambodia, where high levels of non-anthropogenic arsenic have been found in many household tubewells.

In Cambodia, many studies have found high arsenic hazard in groundwater drinking water sources (Polya et al. 2003, 2005; Feldman et al. 2007; Berg et al. 2007; Buschmann et al. 2007; Polya et al. 2008; Sampson et al. 2008; Kocar et al. 2008; Quicksall et al. 2008; Rowland et al. 2008; Benner et al. 2008; Sthiannopkao et al. 2008; Polizzotto et al. 2008). Human exposure has been demonstrated through studies of various biomarkers (Kubota et al. 2006; Gault et al. 2008) and cases of arsenic poisoning (arsenicosis) have been recorded by Mazumder et al. (2009), amongst others. It is estimated that over 100,000 people are exposed in Cambodia, with the majority of those people living in Kandal province (Sampson et al. 2008).

Chronic arsenic exposure can lead to a wide range of health consequences such as lung, bladder, liver and skin cancers, skin hyperpigmentation and keratosis (NRC 1999, 2001; IARC 2004). Many arsenic attributable health outcomes are not contemporaneous with exposure; where data are readily available, such as in Chile, childhood exposures have been linked through detailed epidemiological studies, to peaks in arsenic attributable deaths occurring decades after the exposure (Steinmaus et al. 2013). Exposure to arsenic contaminated drinking water is thus a serious public health concern in Cambodia, both now and for the future (Fredericks 2004). Due to the long latency period of arsenic poisoning as well as the lack of information possessed by the rural villagers most likely to be effected, the full scope of arsenicosis is not fully known.

Arsenic is predominately found in deeper tubewell sources (where a narrow, deep hole is drilled into the ground and connected to a hand pump) rather than shallower dug wells. The distribution of arsenic in the groundwater of Kandal is highly heterogeneous (Lado et al. 2008; Winkel et al. 2008; Sovann and Polya 2014) which, when combined with the fact that arsenic is tasteless, has led to some confusion amongst households concerning the safety of drinking water.

An extensive testing program conducted by the local organisation Resource Development International (RDI) has been operating a testing and education project in the region to provide households with information on the safety of their drinking water. In addition, the pumps of wells which have tested positive for high levels of arsenic $(>50 \mu \mathrm{g} / \mathrm{l})$ have been painted red so as to alert others to the dangers posed by drinking the water.

The sampling strategy for this study was to target households which had been tested for arsenic by RDI. Households in the sample therefore include those with water sources which have tested positive for high levels of arsenic $(>50 \mu \mathrm{g} / \mathrm{l})$ and have changed their water source, those whose drinking water has tested positive and have not changed, as well as those whose water has tested negative for high levels of arsenic. Households were randomly sampled from 3 communes within Kandal Province, shown in Fig. 1.

The households sampled for the study were asked to imagine a hypothetical situation where their current drinking water source had become unusable. They were then presented with 6 choice cards each containing three different tubewells which were available to the household as a drinking water source. Each tubewell was described as being on communal land, with each source being approximately the same distance from the house. The water sources were defined in terms of the taste/appearance of the water, the lifetime cancer risk due to arsenic from the source and the payment that they were required to make to access the source. Attribute levels are shown in Table 1 and examples of choice cards are illustrated in Fig. 2.

Given that the status-quo was unavailable as part of the choice scenario, this was a 'forcedchoice' situation for the respondent. A forced-choice scenario was chosen due to a lack of 


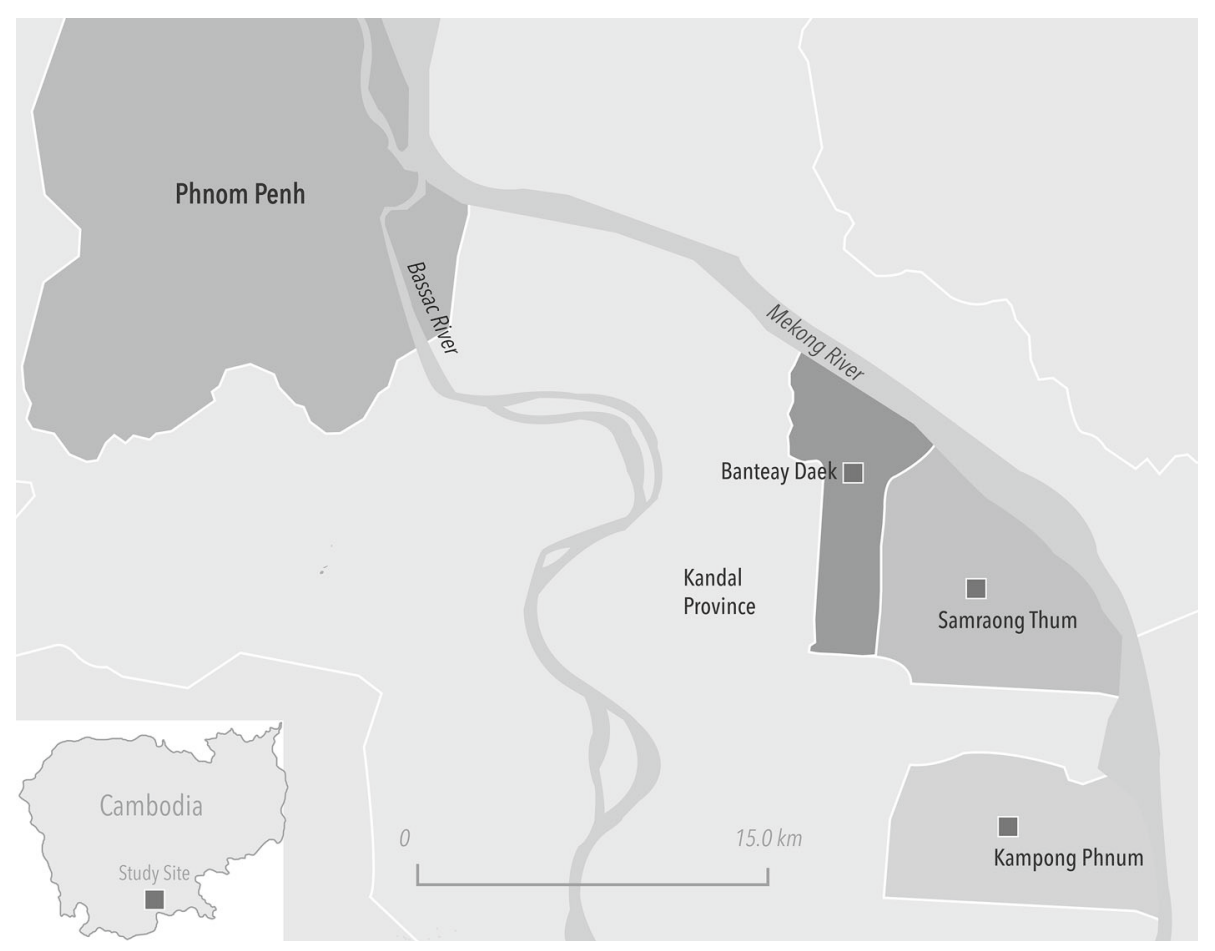

Fig. 1 Data collection sites

Table 1 Attributes, levels and coding

\begin{tabular}{llr}
\hline Attribute & Levels & Coding \\
\hline Taste/appearance & Dark with bad taste & 2 \\
& Cloudy with OK taste & 1 \\
& Clear with good taste & 0 \\
Lifetime cancer risk attributable to arsenic in water & $10 / 500$ & 10 \\
& $5 / 500$ & 5 \\
& $1 / 500$ & 1 \\
(A) Work hours (per week) 171 households & $0 / 500$ & 5 \\
& $5 \mathrm{~h}$ & 3 \\
(B) Money (per month) 174 households & $3 \mathrm{~h}$ & 1 \\
& $1 \mathrm{~h}$ & 50 \\
& 50,000 riels & 30 \\
\hline
\end{tabular}




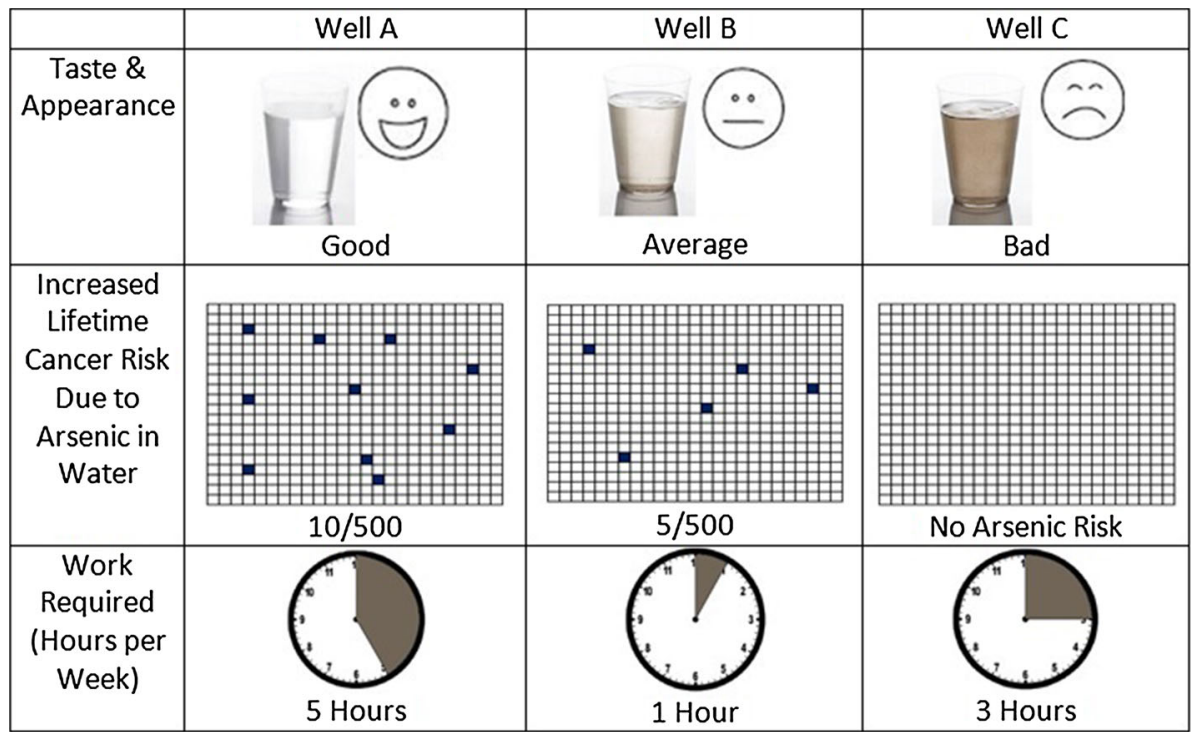

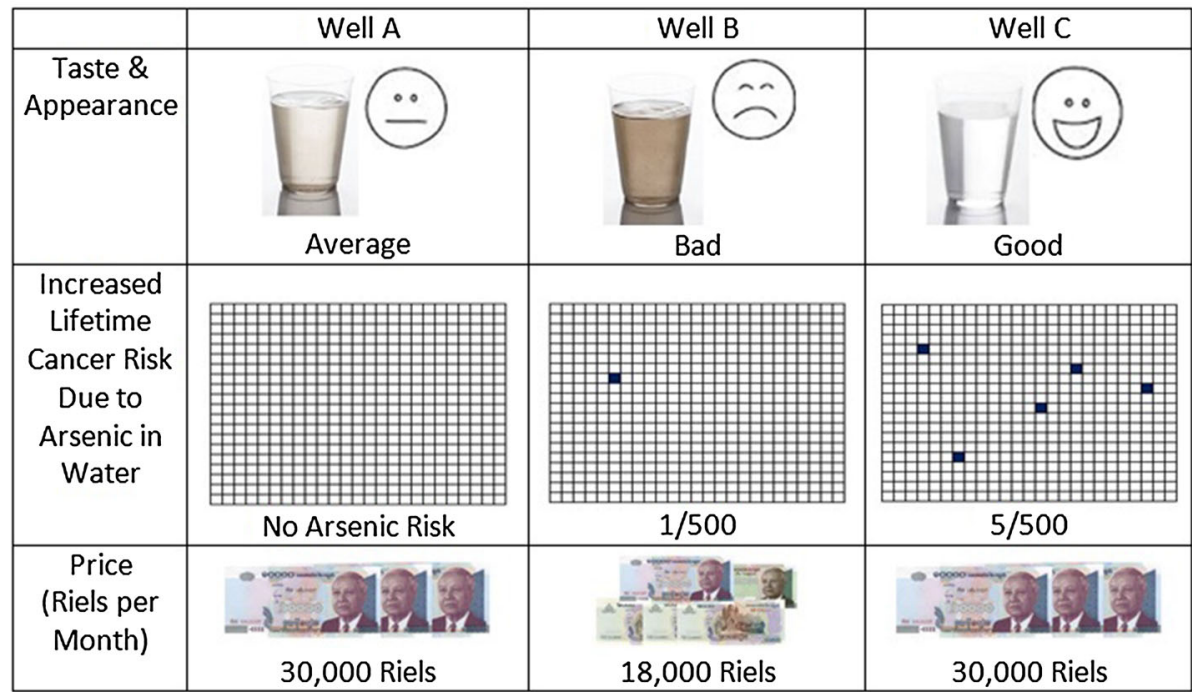

Fig. 2 Example of choice card shown to WAP and MAP samples

precise risk information related to the current water source that the household used. Forced choice scenarios have particularly been utilised in DCE studies which examine preferences for water, such as drinking water (Hensher et al. 2005) or irrigation (Rigby et al. 2010), as water is an essential resource which households can not go without. The primary focus of the DCE was to obtain WTP estimates for risk reductions concerning arsenic exposure and so the household's current water source was not included as a status quo due to the uncertainty that this would create in the choice set.

The piloting of the survey consisted of two sections. Firstly a period of formal household interviews was conducted in July 2012 to ascertain appropriate attributes and levels for the 
DCE and to trial survey formats. The second stage of piloting was conducted in early May 2013 and consisted of full trials of the survey design. A Bayesian Efficient experimental design was generated, using weakly informative priors, with the software Ngene (Rose et al. 2009). This enabled estimation of more informed priors, from the pilot, for the final experimental design.

171 households were presented with choice cards showing 3 wells with weekly work hours as the payment medium. The levels of this attribute were chosen to reflect time spent collecting drinking water for rural households in the dry season, using data from the Cambodian Socio-Economic Survey (CSES), 2009. ${ }^{2}$ The work tasks were described as unskilled jobs that benefited the community such as leveling the roads, fetching drinking water or collecting firewood for households unable to do so. The tasks thus involved working towards improvements of both common goods and private goods. 174 households were presented with choice questions using money as the payment medium. The levels of this attribute were chosen using questionnaire data from CSES 2009 to reflect payments of rural households to water vendors.

Households were chosen at random from the database of RDI, the NGO which runs the arsenic testing and education project. GPS co-ordinates were used to identify the households for interview. In order to achieve an efficient data collection period, households were selected from villages either side of Highway 1 in Kandal province, South East of Phnom Penh. The questionnaire was administered by students of Royal University of Phnom Penh and the Royal University of Agriculture in Cambodia over a 10-day period and the average interview lasted approximately $45 \mathrm{~min}$. The questionnaire was composed of the following sections:

- Household composition, demographics and health questions.

- Arsenic knowledge and result of water test questions.

- Water source usage and characteristics of water sources used (smell, taste, price etc) questions.

- Choice experiment.

- Household Income and agricultural production questions.

Descriptive statistics for the households interviewed are shown in Table 2, broken down by which payment vehicle they were presented with in the choice task.

\section{Empirical Analysis and Results}

The compensating variation measure of welfare can be illustrated for WTP and WTW using the indirect utility function, as shown by Vondolia et al. (2014) and Eom and Larson (2006).

$$
V\left(y-W T P, \mathbf{p}, q_{1} ; Z\right)=V\left(y, \mathbf{p}, q_{0} ; Z\right)
$$

Here the maximum WTP for an improved water source $\left(q_{1}\right)$ is the amount of money which equates the indirect utility function with the utility the household receives at the same prices with the original water source $\left(q_{0}\right)$. Z represents socio-economic characteristics which influence utility.

$$
V\left(l-W T W, \mathbf{p}, q_{1} ; Z\right)=V\left(l, \mathbf{p}, q_{0} ; Z\right)
$$

In the above equation maximum WTW is the amount of time a household would contribute to receive the improved source that equates utility with utility from the original water source without the labour payment.

${ }^{2}$ See http://www.nis.gov.kh/nada/index.php/catalog/CSES. 
Table 2 Summary of respondents by payment vehicle

\begin{tabular}{|c|c|c|c|}
\hline & MAP & WAP & Total \\
\hline \multirow[t]{2}{*}{ Age of respondent } & 48.86 & 46.68 & 47.78 \\
\hline & $(14.81)$ & $(15.45)$ & $(15.17)$ \\
\hline \multirow[t]{2}{*}{ Gender of respondent $(0$-female, 1 -male $)$} & 0.355 & 0.331 & 0.343 \\
\hline & $(0.478)$ & $(0.471)$ & $(0.475)$ \\
\hline \multirow[t]{2}{*}{ Years of education } & 4.744 & 5.148 & 4.944 \\
\hline & $(3.814)$ & $(3.351)$ & $(3.597)$ \\
\hline \multirow[t]{2}{*}{ Can the respondent read? ( $0-$ no, $1-$ yes $)$} & 0.657 & 0.787 & 0.721 \\
\hline & $(0.475)$ & $(0.410)$ & $(0.448)$ \\
\hline \multirow[t]{2}{*}{ Can the respondent write? ( $0-$ no, $1-$ yes $)$} & 0.634 & 0.769 & 0.701 \\
\hline & $(0.482)$ & $(0.421)$ & $(0.458)$ \\
\hline \multirow[t]{2}{*}{ Health of respondent (5-very good, 3 -average, 0 - very bad) } & 3.064 & 2.982 & 3.023 \\
\hline & $(0.815)$ & $(0.846)$ & $(0.832)$ \\
\hline \multirow[t]{2}{*}{ Lost more than 2 weeks work due to illnes? ( 0 -no, 1 -yes $)$} & 0.343 & 0.314 & 0.328 \\
\hline & $(0.475)$ & $(0.464)$ & $(0.470)$ \\
\hline \multirow[t]{2}{*}{ Smokes? (0-no, 1-yes) } & 0.233 & 0.178 & 0.205 \\
\hline & $(0.423)$ & $(0.382)$ & $(0.404)$ \\
\hline \multirow[t]{2}{*}{ Household size } & 5.087 & 5.077 & 5.082 \\
\hline & $(1.898)$ & $(1.771)$ & $(1.836)$ \\
\hline \multirow[t]{2}{*}{ Ln (total household income) } & 12.85 & 13.11 & 12.98 \\
\hline & $(3.373)$ & $(3.226)$ & $(3.303)$ \\
\hline \multirow[t]{2}{*}{ Is arsenic fatal? ( 0 -no, 1 -yes $)$} & 0.913 & 0.923 & 0.918 \\
\hline & $(0.282)$ & $(0.267)$ & $(0.275)$ \\
\hline \multirow[t]{2}{*}{ Know someone with arsenic poisoning? ( 0 -no, 1 -yes $)$} & 0.0988 & 0.0947 & 0.0968 \\
\hline & $(0.298)$ & $(0.293)$ & $(0.296)$ \\
\hline \multirow[t]{2}{*}{ Water supply test positive for high arsenic $(>50 \mathrm{ppb}) ?$} & 0.640 & 0.769 & 0.704 \\
\hline & $(0.480)$ & $(0.421)$ & $(0.457)$ \\
\hline \multirow[t]{2}{*}{ Subjective arsenic risk (/500) } & 121.1 & 132.0 & 126.5 \\
\hline & $(193.8)$ & $(184.9)$ & $(189.5)$ \\
\hline Observations & 174 & 171 & 345 \\
\hline
\end{tabular}

Mean of each variable with standard deviation in parentheses

In the two equalities above $y$ and $l$ represent the full income of the households. i.e. the value of the time endowment and the household income. Similarly the prices $(p)$ represent 'full prices'. In the WTP statement the full income is presented in money units whereas in the WTW statement full income is represented in labour units. See Eom and Larson (2006) for further discussion and details.

\subsection{Willingness to Pay and Willingness to Work}

Analysis of respondent choices is based on Random Utility Theory (RUT). We begin the analysis of choice with the following attributes-based utility specifications for the MAP and WAP samples. 


$$
\begin{aligned}
& U_{n j}=\beta_{1} \text { Taste }_{n j}+\beta_{2} \text { Risk }_{n j}+\beta_{3} \text { Money }_{n j}+\varepsilon_{i} \\
& U_{n j}=\beta_{1} \text { Taste }_{n j}+\beta_{2} \text { Risk }_{n j}+\beta_{3} \text { Work }_{n j}+\varepsilon_{i}
\end{aligned}
$$

Here the utility gained from option $j$ by person $n$ is a function of the three attributes which define the wells in addition to an error term. The choice between alternatives is therefore probabilistic and the option leading to the highest utility is selected by the respondent. This is illustrated in (5). These utility functions, being linear and additively separable can be used, along with the assumption that the error terms follow a type I extreme value distribution, to specify the conditional logit model (6).

$$
\begin{gathered}
P_{n i}=P\left(\varepsilon_{n j}-\varepsilon_{n i}<X_{n i} \beta-X_{n j} \beta\right) \quad \forall j \neq i \in J \\
P_{n i}=\frac{\exp \left(\mu X_{n i} \beta\right)}{\sum_{j=1}^{J} \exp \left(\mu X_{n j} \beta\right)}
\end{gathered}
$$

The conditional logit model shown in equation (6) assumes constant error variance across all individuals in the sample where the scale term is inversely proportional to the error term $\left(\mu=\frac{\pi}{\sqrt{6 \sigma_{\varepsilon}^{2}}}\right)$. An alternative model allows for heteroscedasticity, i.e. unequal error variance between individuals (Hensher et al. 1999; DeShazo and Fermo 2002). This is illustrated in (7) where the scale term $(\mu)$ now varies between individuals $\left(\mu_{n}\right)$.

$$
P_{n i}=\frac{\exp \left(\mu_{n} X_{n i} \beta\right)}{\sum_{j=1}^{J} \exp \left(\mu_{n} X_{n j} \beta\right)}
$$

The scale term is parameterised with individual level variables $(\mathrm{Z})$.

$$
\mu_{n}=\exp \left(Z_{n} \gamma\right)
$$

There are now $\beta$ and $\gamma$ parameters to be estimated via maximising the log likelihood function $\left(L L=\sum_{n=1}^{N} \sum_{j=1}^{J} y_{n j} \ln P_{n i}\right.$ where $y_{n j}$ is an indicator variable which is a 1 if option $j$ is chosen or zero otherwise). Estimation of the heteroscedastic conditional logit model allows the analysis of choice consistency between different groups of individuals, where an equal consistency suggests homoscedasticity.

The parameter estimates for the heteroscedastic conditional logit models for the WAP and MAP samples are presented in Table 3. All attribute coefficients (the upper portion of the table) are statistically significant at the $99 \%$ level and have signs consistent with a priori hypotheses. Improved levels of taste/appearance, lower risk and lower payment, either in terms of money or labour hours, lead to increased utility. The parameter estimates for the scale term indicate that for the MAP sample, the scale term is lower (and the error variance higher) for those households who have been told that they have high levels of arsenic $(>50 \mu \mathrm{g} / \mathrm{l})$ in their water source and if the respondent has good health. This indicates a lower choice consistency relative to households who have not received a positive test for high arsenic and where the respondent has lower health levels.

With the WAP sample, the scale term parameters indicate that health has the same relationship on choice consistency as in the MAP sample, better health is associated with lower choice consistency. Further, variables indicating if the respondent is able to read and if high levels of arsenic are found in the household's water supply, are associated with higher levels of choice consistency.

In order to check the models for a coherent ranking of parameter magnitudes, the models are re-estimated using the dummy variables for the levels of the attributes. The results of these are presented in Table 4. The parameter estimates for the choice attributes are all statistically significant and have an appropriate ranking. Hypothesis tests reject parameter equivalence 
Table 3 Heteroscedastic conditional logit models
Standard errors in parentheses

$* p<0.10$; ** $p<0.05$;

$* * * p<0.01$

\begin{tabular}{lll}
\hline & $(1)$ & $(2)$ \\
\hline Taste/appearance & $-0.961 * * *$ & $-0.535 * * *$ \\
& $(0.281)$ & $(0.139)$ \\
Risk & $-0.642^{* * *}$ & $-0.318^{* * *}$ \\
& $(0.173)$ & $(0.079)$ \\
Payment (money) & $-0.062^{* * *}$ & \\
& $(0.021)$ & \\
Payment (work) & & $-0.164 * * *$ \\
& & $(0.043)$ \\
Scale & & $0.236 *$ \\
Arsenic in water & $-0.434 * * *$ & $(0.140)$ \\
& $(0.116)$ & $0.325 * *$ \\
Read & 0.019 & $(0.149)$ \\
& $(0.123)$ & $-0.130 * *$ \\
Health & $-0.149 * *$ & $(0.064)$ \\
11 & $(0.071)$ & -883.259 \\
$\mathrm{~N}$ & -876.441 & 3078 \\
\hline
\end{tabular}

which indicates that the choice behaviour of both samples are sensitive to the different arsenic risk levels.

The parameter estimates from the choice models can be used to estimate marginal willingness to pay (MWTP) values for risk reduction or taste/appearance improvement either in terms of money or work hours for the relevant samples. For instance, the WTP for marginal risk reduction with money as payment vehicle is:

$$
M W T P_{\text {risk }}=-\beta_{\text {risk }} / \beta_{\text {money }}
$$

Utilising the Krinsky-Robb simulation method to estimate WTP/WTW standard errors and $95 \%$ confidence intervals, we estimate MWTP shown in the lower portion of Table 5. The results indicate that, using the linear utility assumption, mean WTP for a 1/500 reduction in lifetime cancer risk is 10,298 riels per month or using the local USD exchange rate (1 USD $=4000$ Riels) about USD 2.57. For a 'unit' increase in taste/appearance the WTP is 15,419 riels per month or USD 3.85 per month. The MWTW estimates for the WAP sample are presented in the upper portion of Table 5. The MWTP for risk reduction in terms of labour is $1.94 \mathrm{~h}$ a week, or $7.76 \mathrm{~h}$ a month.

\subsection{Testing the Equivalence of WTP and WTW}

In order to compare the two payment vehicles, we must consider how the respondents are valuing their time when responding to the choice task. There are however several alternative scenarios to consider in placing a monetary value on time. One potential method of valuing the labour contributions of the respondents is to consider the market wages for the actual tasks, within the survey, required to be undertaken for access to the water. These tasks were described to the respondents as unskilled manual tasks which included helping to collect firewood, transport water and leveling roads. 
Table 4 Heteroscedastic conditional logit models (levels)
Table 5 MWTP estimates for MAP and WAP samples

\begin{tabular}{|c|c|c|}
\hline & (3) & (4) \\
\hline Taste/appearance (OK) & $\begin{array}{l}-0.727 * * * \\
(0.262)\end{array}$ & $\begin{array}{l}-0.491 * * * \\
(0.160)\end{array}$ \\
\hline Taste/appearance (bad) & $\begin{array}{l}-2.520 * * * \\
(0.677)\end{array}$ & $\begin{array}{l}-1.377 * * * \\
(0.348)\end{array}$ \\
\hline Risk $1 / 500$ & $\begin{array}{l}-2.258 * * * \\
(0.576)\end{array}$ & $\begin{array}{l}-1.075^{* * *} \\
(0.276)\end{array}$ \\
\hline Risk 5/500 & $\begin{array}{l}-5.331 * * * \\
(1.320)\end{array}$ & $\begin{array}{l}-2.010 * * * \\
(0.476)\end{array}$ \\
\hline Risk 10/500 & $\begin{array}{l}-7.927 * * * \\
(1.958)\end{array}$ & $\begin{array}{l}-3.808 * * * \\
(0.904)\end{array}$ \\
\hline Payment (money) & $\begin{array}{l}-0.113 \text { *** } \\
(0.031)\end{array}$ & \\
\hline Payment (work) & & $\begin{array}{l}-0.204 * * * \\
(0.051)\end{array}$ \\
\hline \multicolumn{3}{|l|}{ Scale } \\
\hline Arsenic in water & $\begin{array}{l}-0.421 * * * \\
(0.107)\end{array}$ & $\begin{array}{l}0.084 \\
(0.129)\end{array}$ \\
\hline Read & $\begin{array}{l}0.040 \\
(0.111)\end{array}$ & $\begin{array}{l}0.317 * * \\
(0.139)\end{array}$ \\
\hline Health & $\begin{array}{l}-0.157 * * \\
(0.065)\end{array}$ & $\begin{array}{l}-0.113 * \\
(0.061)\end{array}$ \\
\hline 11 & -827.094 & -851.793 \\
\hline $\mathrm{N}$ & 3132 & 3078 \\
\hline
\end{tabular}

\begin{tabular}{lcr}
\hline & Appearance & \multicolumn{1}{c}{ Risk } \\
\hline MWTW (h/week) & -3.264 & -1.940 \\
Lower level (work) & -4.515 & -2.516 \\
Upper level (work) & -2.375 & -1.563 \\
MWTP (riels/month) & -15.419 & -10.298 \\
Lower level (money) & -26.743 & -17.609 \\
Upper level (money) & -10.344 & -7.579 \\
\end{tabular}

Although the markets for these tasks may not be complete, meaning that actual external employment opportunities for the household members in these activities may be limited, the households may have an idea of the going rate for these activities or at least the minimum wage that they would require to perform these tasks.

To examine whether the household might be comparing their willingness to work with the actual monetary remuneration that could be expected from these tasks, wage data from the Cambodian Socio-Economic survey (2009) is utilised. As part of this survey the heads of villages were asked questions related to village wages. Presented in Table 6 are summary statistics for the mean per day wages for four relatively unskilled manual tasks, provided by the heads of rural villages in Kandal province. 
Table 6 Daily wage rates Kandal province (CSES, 2009)

\begin{tabular}{llr}
\hline Task & Males & Females \\
\hline Transplanting of paddy & $12,375.02$ & $12,394.23$ \\
Caring for Crops & $12,074.07$ & $11,000.00$ \\
Harvesting & $12,915.09$ & $13,179.25$ \\
Unskilled construction & $13,348.84$ & 8364.29 \\
\hline
\end{tabular}

\begin{tabular}{llr}
\hline Hours per day & Hourly pay (riels) & Monetised WTW (per month) \\
\hline 10 & 1250 & 9700.00 \\
8 & 1563 & $12,128.88$ \\
\hline
\end{tabular}

Table 7 Monetised WTW estimates using a riels 12,500 daily wage and different daily working hour assumptions

Using 12,500 as an approximate daily wage for the activities described to the respondents we can estimate an hourly market wage rate for the labour tasks. In order to do this we require an approximation of daily working hours. Data from the sample suggests that between 8 and $10 \mathrm{~h}$ is common. Using these hours per day, hourly market wages are as in Table 7.

In order to further test the payment vehicles for any inherent utility differences which may lead to different marginal utilities, the data was pooled using the wage data to monetise the working hour attributes in the data set. By pooling the data we are able to estimate the parameters from the utility function in the equation below:

$$
\begin{aligned}
U_{n j}= & \beta_{1} \text { Taste }_{n j}+\beta_{2} \text { Risk }_{n j}+\beta_{3} \text { Payment }_{n j}+\beta_{4} \text { Taste }_{n j} . W A P_{i} \\
& +\beta_{5} \text { Risk }_{n j} . W A P_{i}+\beta_{6} \text { Payment }_{n j} . W A P_{i}+\varepsilon_{i}
\end{aligned}
$$

The WAP variable is a dummy variable representing if the payment vehicle used for the respondent was work hours. Individual and joint insignificance of these interaction variables would indicate no differences in utility due to the payment vehicle and that the two samples can be pooled. The final attributes and levels for the pooled data set is shown in Table 8 .

By estimating the pooled model we can test that the choice of payment vehicle has an effect on the utility that a person derives from the attributes. We test the null hypothesis that there is no effect against the two-sided alternative hypothesis that the choice of payment vehicle does have a utility impact.

$$
\begin{aligned}
& H_{0}: \beta_{4}=\beta_{5}=\beta_{6}=0 \\
& H_{A}: \beta_{4}, \beta_{5}, \beta_{6} \neq 0
\end{aligned}
$$

In addition to the estimation and testing of the interaction variables we also test for differences in scale (i.e. heteroscedasticity) due to the payment vehicle. In order to test for any payment vehicle effects a parameterised heteroscedastic conditional logit model is estimated. The models are presented in Table 9 as models 5 and 6.

All the interaction variables and scale terms are insignificant indicating that the choice of payment vehicle does not lead to any direct differences in marginal utility or choice consistency. The two payment vehicles are equivalent in this regard. The equivalence result from these tests is perhaps not surprising given the between sample exchange rate, or shadow wage rate: 
Table 8 Attributes, levels and coding (pooled samples)

\begin{tabular}{|c|c|c|c|}
\hline Attribute & Label & Levels & Coding \\
\hline \multirow[t]{3}{*}{ Taste and appearance } & \multirow[t]{3}{*}{ Taste } & Dark with bad taste & 2 \\
\hline & & Cloudy with OK taste & 1 \\
\hline & & Clear with good taste & 0 \\
\hline \multirow{4}{*}{$\begin{array}{l}\text { Lifetime cancer risk } \\
\text { attributable to arsenic } \\
\text { in water }\end{array}$} & \multirow[t]{4}{*}{ Risk } & $10 / 500$ & 10 \\
\hline & & $5 / 500$ & 5 \\
\hline & & $1 / 500$ & 1 \\
\hline & & $0 / 500$ & 0 \\
\hline \multirow{7}{*}{$\begin{array}{l}\text { Payment (money } \\
\text { or monetised } \\
\text { work) }\end{array}$} & \multirow[t]{7}{*}{ Payment } & 50,000 riels & 50 \\
\hline & & 30,000 riels & 30 \\
\hline & & 18,000 riels & 18 \\
\hline & & 6000 riels & 6 \\
\hline & & $5 \mathrm{~h}=25,000$ riels & 25 \\
\hline & & $3 \mathrm{~h}=15,000$ riels & 15 \\
\hline & & $1 \mathrm{~h}=5000$ riels & 5 \\
\hline \multirow[t]{2}{*}{ Work as payment } & \multirow[t]{2}{*}{ WAP } & Work & 1 \\
\hline & & Money & 0 \\
\hline
\end{tabular}

Table 9 Pooled models

\begin{tabular}{lll}
\hline & $(5)$ & $(6)$ \\
\hline Taste/appearance & $-0.484 * * *$ & $-0.526^{* * *}$ \\
& $(0.055)$ & $(0.045)$ \\
Risk & $-0.334^{* * *}$ & $-0.329 * * *$ \\
& $(0.023)$ & $(0.023)$ \\
Payment & $-0.039^{* * *}$ & $-0.038^{* * *}$ \\
& $(0.007)$ & $(0.006)$ \\
WAP.Payment & 0.006 & 0.006 \\
& $(0.008)$ & $(0.006)$ \\
WAP.Taste & -0.090 & \\
WAP.Risk & $(0.076)$ & \\
Scale & 0.003 & \\
WAP & $(0.030)$ & 0.014 \\
ll & & $(0.088)$ \\
N & & -1777.187 \\
& & 6210 \\
\end{tabular}




$$
\frac{W T P}{W T W}=\frac{10,298 \text { Riels } / \text { Month }}{7.76 \mathrm{hrs} / \text { Month }}=1327.06 \text { Riels } / \mathrm{hr}
$$

The exchange rate between the samples, 1327.06 Riels/hour, is extremely similar to the market wage rate for the labour tasks that we used for monetising the work time attribute. The shadow wage rate that the respondents seem to be utilising is highly similar to the market value of the labour tasks in question, in addition to the consistencies in choice behaviour exemplified by the parameter estimate parities from the pooled model.

An alternative method for monetising the WTW estimates is to use the approach taken by O'Garra (2009) and Arbiol et al. (2013) which is based on work by Cesario (1976). In these studies the authors use one third of the working wage rates as the opportunity cost of time as they argue that households will be substituting current leisure time for the required work hours, rather than time already spent in work. This low wage rate would lead to a monetised WTW estimate substantially lower than the money based WTP estimate. The assumption that households would be substituting leisure time rather than productive time such as agricultural or household work time is doubtful in situations of full markets.

In full markets the literature on agricultural household models suggests that household members will consume leisure up to the point where the monetised marginal utility of leisure is equal to the market wage rate. The opportunity cost of time is therefore the full market wage rate, rather than some fraction. In situations where there are missing labour markets, households will consume leisure up to the point where the monetised marginal utility of leisure is equal to the marginal revenue product of labour on the farm or the off-farm wage rate they can receive. The shadow wage rate in this situation is therefore dependent on the specific technology of the farm. Our results thus suggest that households are responding as if there are well functioning labour markets.

\subsection{Latent Class Analysis}

The use of different mediums of exchange in the choice experiment raises the question of how the payment vehicle used in the DCE might impact choice behaviour. Given the arguments about the inappropriateness of money as a payment vehicle in rural developing contexts, one way in particular that the change in payment attribute may affect choice behaviour is through protest votes or non-engagement with the choice tasks. As this DCE has no status quo option (protest route $\mathrm{v}$ ) and high response rates and zero drop outs were achieved (protest route iv), 3 likely ways in which non-engagement or protest, due to the payment vehicle, could be channeled are: (i) ignoring the payment attribute, regardless of the level, when making their selection from the choice set (i.e. not attend the price attribute), (ii) using a heuristic such as choosing the lowest priced alternative and, (iii) choosing randomly. The significant and coherent parameter estimates presented in Tables 3, 4 and 9, suggest that protest nonengagement was not manifest as (ii) or (iii). However, the models in Tables 3, 4 and 9 are aggregate models which may mask protest or non-compensatory choice behaviour by subsets of the overall sample. Estimation of latent class models allows identification of alternative preference and/or choice structures, including the protest behaviours described above and also whether attribute non-attendance (ANA) towards the payment vehicle (i) is different between the labour and work choice experiments.

In this section we present the results of latent class choice models and examine ANA differences or similarities between the MAP and WAP samples. Latent class models further allow the extension of the analysis to incorporate preference heterogeneity. 
Table 10 Information criteria for alternative class specifications

\begin{tabular}{lllllll}
\hline Number of Classes & LL & BIC(LL) & AIC3(LL) & CAIC(LL) & NPar & $d f$ \\
\hline MAP & & & & & & \\
1 & -886.343 & 1788.163 & 1781.686 & 1791.163 & 3 & 171 \\
2 & -807.840 & 1656.952 & 1117.679 & 1664.952 & 8 & 166 \\
3 & -754.234 & 1575.536 & 1547.468 & 1588.536 & 13 & 161 \\
$4^{*}$ & -733.809 & 1560.481 & 1521.618 & 1578.481 & 18 & 156 \\
5 & -732.918 & 1584.493 & 1534.835 & 1607.493 & 23 & 151 \\
6 & -724.237 & 1592.928 & 1532.473 & 1620.927 & 28 & 146 \\
$W A P$ & & & & & & \\
1 & -889.887 & 1795.198 & 1788.773 & 1798.198 & 3 & 168 \\
2 & -789.878 & 1620.889 & 1603.756 & 1628.889 & 8 & 163 \\
3 & -757.953 & 1582.747 & 1554.905 & 1595.747 & 13 & 158 \\
$4 *$ & -743.073 & 1578.696 & 1540.146 & 1596.696 & 18 & 153 \\
5 & -735.189 & 1588.636 & 1539.378 & 1611.636 & 23 & 148 \\
6 & -724.413 & 1592.793 & 1532.826 & 1620.793 & 28 & 143 \\
\hline
\end{tabular}

* Selected models

In the latent class model the choice probabilities and the marginal utilities are conditional on being in class $\mathrm{c}$. The latent class choice model is thus:

$$
P_{i n t \mid c}=\frac{\exp \left(\lambda \beta_{c} X_{i n}\right)}{\sum_{j=1}^{J} \exp \left(\lambda \beta_{c} X_{i n}\right)}
$$

Class membership is modeled using a multinomial logit form with a vector of individual respondent characteristics $(Z)$ as explanatory variables

$$
P_{n c}=\frac{\exp \left(Z_{n} \phi\right)}{\sum_{c=1}^{C} \exp \left(Z_{n} \phi\right)}
$$

Identification is achieved by imposing $\sum \phi=0$.

The fit statistics for latent class choice models with varying preference class numbers are presented in Table 10 .

The first similarity between the two sub-samples is that the information criteria, used to aid model selection for non-nested models, suggests that there are 4 underlying preference classes in both the money and labour sub samples. The parameters form the 4 preference class choice models are presented in Table 11.

Focusing first on the MAP sample, the class 1 attribute parameter estimates have expected signs on quality and risk, however the cost term has a positive sign which indicates that respondents who are members of this class have a positive marginal utility for higher prices on wells. Households who have received a positive test for high levels of arsenic in their water source are less likely than those who have negative results to be members of this class.

Class 2, which accounts for $28.97 \%$ of the sample has an insignificant parameter estimate for the money variable indicating that these respondents were ignoring, or non-attending, this 
Table 11 Latent class choice models-(A) MAP and (B) WAP

\begin{tabular}{|c|c|c|c|c|}
\hline & Class 1 & Class 2 & Class 3 & Class 4 \\
\hline \multicolumn{5}{|l|}{$M A P$} \\
\hline Taste/appearance & $\begin{array}{l}-2.082 * * * \\
(0.526)\end{array}$ & $\begin{array}{l}-1.062^{* * * *} \\
(0.171)\end{array}$ & $\begin{array}{l}0.002 \\
(0.193)\end{array}$ & $\begin{array}{l}-0.425^{* * *} \\
(0.141)\end{array}$ \\
\hline Risk & $\begin{array}{l}-5.072 * * * \\
(1.015)\end{array}$ & $\begin{array}{l}-0.209 * * * \\
(0.049)\end{array}$ & $\begin{array}{l}-0.629 * * * \\
(0.115)\end{array}$ & $\begin{array}{l}-0.203 * * * \\
(0.072)\end{array}$ \\
\hline Price & $\begin{array}{l}1.088 * * * \\
(0.231)\end{array}$ & $\begin{array}{l}0.000 \\
(0.013)\end{array}$ & $\begin{array}{l}-0.067 * * * \\
(0.025)\end{array}$ & $\begin{array}{l}-0.091 * * * \\
(0.023)\end{array}$ \\
\hline \multicolumn{5}{|l|}{ Class membership } \\
\hline Intercept & $\begin{array}{l}0.990 * * * \\
(0.354)\end{array}$ & $\begin{array}{l}1.159 * * * \\
(0.393)\end{array}$ & $\begin{array}{l}-0.400 \\
(0.555)\end{array}$ & $\begin{array}{l}-1.749 * * \\
(0.812)\end{array}$ \\
\hline Positive for high arsenic (>50 ppb) & $\begin{array}{l}-0.895 * * \\
(0.407)\end{array}$ & $\begin{array}{l}-1.428 * * * \\
(0.417)\end{array}$ & $\begin{array}{l}0.644 \\
(0.560)\end{array}$ & $\begin{array}{l}1.679 * * \\
(0.377)\end{array}$ \\
\hline LL & -733.809 & & & \\
\hline $\mathrm{BIC}$ & 1560.481 & & & \\
\hline AIC3 & 1521.618 & & & \\
\hline Class size $(\%)$ & 31.64 & 28.97 & 23.73 & 15.66 \\
\hline \multicolumn{5}{|l|}{$W A P$} \\
\hline Taste/appearance & $\begin{array}{l}-0.551 * * * \\
(0.0712)\end{array}$ & $\begin{array}{l}-1.798 * * * \\
(0.558)\end{array}$ & $\begin{array}{l}-1.891 * * * \\
(0.4831)\end{array}$ & $\begin{array}{l}-7.802 * \\
(4.509)\end{array}$ \\
\hline Risk & $\begin{array}{l}-0.3184 * * * \\
(0.028)\end{array}$ & $\begin{array}{l}-4.638 * * * \\
(0.934)\end{array}$ & $\begin{array}{l}-0.044 \\
(0.097)\end{array}$ & $\begin{array}{l}-1.226^{*} \\
(0.707)\end{array}$ \\
\hline Work & $\begin{array}{l}-0.306^{* * *} \\
(0.029)\end{array}$ & $\begin{array}{l}-0.124 \\
(0.126)\end{array}$ & $\begin{array}{l}-0.220 \\
(0.160)\end{array}$ & $\begin{array}{l}2.076^{*} \\
(1.116)\end{array}$ \\
\hline \multicolumn{5}{|l|}{ Class membership } \\
\hline Intercept & $\begin{array}{l}0.818 * * * \\
(0.227)\end{array}$ & $\begin{array}{l}0.246 \\
(0.249)\end{array}$ & $\begin{array}{l}-0.274 \\
(0.305)\end{array}$ & $\begin{array}{l}-0.791 * * \\
(0.359)\end{array}$ \\
\hline Ln agricultural income & $\begin{array}{l}0.071 * * \\
(0.028)\end{array}$ & $\begin{array}{l}0.051 * \\
(0.029)\end{array}$ & $\begin{array}{l}-0.083 \\
(0.057)\end{array}$ & $\begin{array}{l}-0.040 \\
(0.051)\end{array}$ \\
\hline LL & -743.073 & & & \\
\hline $\mathrm{BIC}$ & 1578.696 & & & \\
\hline AIC3 & 1540.146 & & & \\
\hline Class size $(\%)$ & 59.80 & 27.76 & 7.3 & 5.15 \\
\hline
\end{tabular}

Standard errors in parentheses

$* p<0.10$;** $p<0.05 ; * * * p<0.01$

attribute or may have negligible utility from this attribute (see for example Scarpa et al. 2009; Lagarde 2013). Those respondents' whose households have received a negative arsenic test are more likely to be a member of Class 2 than those with a positive result.

Class 3 has an insignificant parameter estimate on quality which indicates that members of this class are either ignoring this attribute, or gain negligible utility from it, and that choice is mainly based on risk and cost. Respondents with poor health are significantly more likely to be a member of Class 3 . 
Class 4 attribute parameter estimates are all significant and have expected signs. It accounts for $15.66 \%$ of the sample and household who have a tubewell source which has tested positive for arsenic are more likely to be members of this class.

Turning now to the WAP sample household, health and water source characteristics were hypothesised to influence class membership. However the only significant covariate was agricultural income (see Table 11).

Class 1 has significant main attribute parameters, with expected signs. Class 3 has a significant parameter estimate for water quality only. Class 4 has low parameter significance for all attributes and a positive parameter estimate for the cost (work). Class 2 in this model represents $27.76 \%$ of the sample and has an insignificant parameter value on the payment vehicle (work). This suggests that the members of this class are non-attending or have low preference for the payment vehicle and are basing their choices on risk and quality. Moreover this class mirrors Class 2 from the money sub sample in both having very similar percentages of the respondents' where the payment vehicle parameter estimate was insignificant whilst all other attribute parameters are significant and intuitively signed.

One potential empirical issue is a confounding of tastes/preference and non-attendance. This potential confounding may lead to a misinterpretation of the insignificant parameter estimate as non-attendance when it could be related to low or insignificant preferences. A commonly used method in the literature is to impose a parameter restriction to account for non-attendance of an attribute in the latent class model (see for instance Burton and Rigby 2009; Scarpa et al. 2009; Campbell et al. 2011; Lagarde 2013). To investigate this issue further we re-estimate the latent class models of Table 11 with the parameters for the money and work attributes constrained to be zero for the MAP and WAP models respectively. The results from these models are shown in Table 12. A likelihood ratio test reveals that the restricted Models in Table 12 are preferred.

The preferred models of Table 12 show very little differences from the unrestricted models of Table 11 in terms of parameter significance, parameter signs, fit statistics and class sizes. The key result, that levels of ANA regarding the payment vehicle are highly similar between the two DCE versions, is retained in the restricted model. This suggests that the choice of payment vehicle does not impact the rate of non-attendance towards the payment vehicle for members of preference Class 2. A stable proportion of the sample does not consider the payment attribute, regardless of the medium of exchange. This result indicates that ignoring the payment vehicle as a form of protest or disengagement is independent of the choice of payment vehicle.

\section{Discussion and Conclusions}

The motivation for this research is the potential downward bias of WTP estimates that use money as a payment vehicle in rural developing economies where ability to pay is limited by a lack of markets, high transaction costs, low incomes and transactions which occur through barter or work exchange. In light of this researchers have begun to explore using labour contributions as a payment vehicle for valuing environmental goods or services. However little attention has been given to choice behaviour differences owing to changes in the units of the payment attribute. In this paper we have presented the results of a randomly assigned splitsample discrete choice experiment using both money and labour contributions as payment vehicles. 
Table 12 Constrained latent class choice models-(A) MAP and (B) WAP

\begin{tabular}{|c|c|c|c|c|}
\hline & Class 1 & Class 2 & Class 3 & Class 4 \\
\hline \multicolumn{5}{|l|}{$M A P$} \\
\hline Taste/appearance & $\begin{array}{l}-2.083 \text { *** } \\
(0.526)\end{array}$ & $\begin{array}{l}-1.063 * * * \\
(0.169)\end{array}$ & $\begin{array}{l}0.003 \\
(0.191)\end{array}$ & $\begin{array}{l}-0.425^{* * *} \\
(0.140)\end{array}$ \\
\hline Risk & $\begin{array}{l}-5.072 * * * \\
(1.015)\end{array}$ & $\begin{array}{l}-0.210 * * * \\
(0.039)\end{array}$ & $\begin{array}{l}-0.629 * * * \\
(0.115)\end{array}$ & $\begin{array}{l}-0.203^{* * *} \\
(0.072)\end{array}$ \\
\hline Price & $\begin{array}{l}1.088^{* * * *} \\
(0.231)\end{array}$ & $\begin{array}{l}0.000 \\
(-)\end{array}$ & $\begin{array}{l}-0.067 * * * \\
(0.025)\end{array}$ & $\begin{array}{l}-0.091 * * * \\
(0.023)\end{array}$ \\
\hline \multicolumn{5}{|l|}{ Class membership } \\
\hline Intercept & $\begin{array}{l}0.992 * * * \\
(0.346)\end{array}$ & $\begin{array}{l}1.162 * * * \\
(0.380)\end{array}$ & $\begin{array}{l}-0.402 \\
(0.553)\end{array}$ & $\begin{array}{l}-1.752 * * \\
(0.805)\end{array}$ \\
\hline Positive for high arsenic (>50 ppb) & $\begin{array}{l}-0.897 * * \\
(0.399)\end{array}$ & $\begin{array}{l}-1.429 * * * \\
(0.415)\end{array}$ & $\begin{array}{l}0.645 \\
(0.559)\end{array}$ & $\begin{array}{l}1.681 * * \\
(0.800)\end{array}$ \\
\hline LL & -733.807 & & & \\
\hline $\mathrm{BIC}$ & 1555.319 & & & \\
\hline AIC3 & 1518.615 & & & \\
\hline Class size $(\%)$ & 31.64 & 29.00 & 23.71 & 15.65 \\
\hline \multicolumn{5}{|l|}{$W A P$} \\
\hline Taste/appearance & $\begin{array}{l}-0.549 * * * \\
(0.071)\end{array}$ & $\begin{array}{l}-1.596^{* * * *} \\
(0.460)\end{array}$ & $\begin{array}{l}-1.887 * * \\
(0.483)\end{array}$ & $\begin{array}{l}-7.525^{*} \\
(4.486)\end{array}$ \\
\hline Risk & $\begin{array}{l}-0.319 * * * \\
(0.029)\end{array}$ & $\begin{array}{l}-4.529 * * * \\
(0.873)\end{array}$ & $\begin{array}{l}-0.044 \\
(0.097)\end{array}$ & $\begin{array}{l}-1.186^{* *} \\
(0.701)\end{array}$ \\
\hline Work & $\begin{array}{l}-0.307 * * * \\
(0.030)\end{array}$ & $\begin{array}{l}0.000 \\
(-)\end{array}$ & $\begin{array}{l}-0.221 \\
(0.160)\end{array}$ & $\begin{array}{l}2.003 * * \\
(1.117)\end{array}$ \\
\hline \multicolumn{5}{|l|}{ Class membership } \\
\hline Intercept & $\begin{array}{l}0.818^{* * *} \\
(0.226)\end{array}$ & $\begin{array}{l}0.246 \\
(0.249)\end{array}$ & $\begin{array}{l}-0.272 \\
(0.304)\end{array}$ & $\begin{array}{l}-0.790^{* *} \\
(0.359)\end{array}$ \\
\hline Ln agricultural income & $\begin{array}{l}0.070 * * \\
(0.028)\end{array}$ & $\begin{array}{l}0.050 * \\
(0.029)\end{array}$ & $\begin{array}{l}-0.083 \\
(0.057)\end{array}$ & $\begin{array}{l}-0.038 \\
(0.052)\end{array}$ \\
\hline LL & -743.652 & & & \\
\hline $\mathrm{BIC}$ & 1574.712 & & & \\
\hline AIC3 & 1538.304 & & & \\
\hline Class size $(\%)$ & 59.84 & 27.61 & 7.33 & 5.23 \\
\hline
\end{tabular}

Standard errors in parentheses

$* p<0.10$;** $p<0.05$; *** $p<0.01$

We find three novel results. Firstly the internal opportunity cost of time is found to be very similar to the market wage rates used in the local area for similar labour tasks. The agricultural household literature indicates that in situations of functioning labour markets the households' shadow wage rate will equal the market wage rate. Our result thus provides evidence of a functioning labour market.

Our second novel finding is that non-attendance of the payment vehicle is consistent between the monetary and labour payment vehicles. Roughly 28-29\% of each sample ignores 
the payment attribute whilst considering the other two attributes. This result indicates that the choice of payment vehicle has less of an impact on valuation estimates than if the payment vehicle itself was leading to non-attendance or low engagement.

Our third novel finding is that we find no significant marginal utility differences or differences in the consistency of choice due to the payment vehicle. The payment vehicle itself is not leading to significantly different levels of noise and choice inconsistency.

The results of these tests indicate that there is little difference between the money or work payment vehicles for estimating welfare values in our study. This finding is different to previous studies where respondents have been found to offer a higher value of time than they do money (e.g. Abramson et al. 2011). Our results provide support for the use of monetary payment vehicles in rural developing country contexts. Further work is warranted to examine the replicability of this finding in other locations. Given the hypothesis that the functionality of labour markets will lead to the convergences of market and shadow wage rates, future research should examine the replicability of the result in areas more remote from urban centres and with varying levels of marketisation. Our study sites, although rural, were situated in villages surrounding a highway which provides a connection to Phnom Penh, with some households located as little as $15 \mathrm{~km}$ away from the edge of the city.

Our findings suggests that, for our study case, respondents have a valuation of time similar to the market value, for similar labour tasks, and the choice of payment vehicle itself does not impact the estimated models in terms of choice probabilities or choice consistency. Given the additional complications and uncertainties interpreting the monetary costs of time in order to monetise labour contributions, WTP would seem the most straightforward economic measure in this circumstance.

In cases where labour markets are missing, or not functioning, which is perhaps the more frequent scenario in rural developing areas, the use of WTW measures should still be explored. In order to utilise these methods however, better methods of estimating shadow costs of time should be developed which allow for variation in opportunity cost over the year, particularly the farming seasons.

Acknowledgements We are very grateful to the hard work and commitment of the interviewers who collected the data for this study. We also would like to thank Lori Frees at RDI Cambodia for helping to organise the logistics of the study and pro- viding comments. We further would like to thank Laura Richards (University of Manchester), Andrew Shantz, Dina Kuy (RDI), Vichet Hang (RUPP) and Chansopheaktra Sovann (RUPP) for helping with data collection logistics as well as useful discussions. The work was supported by a $\mathrm{PhD}$ studentship and grant from the Sustainable Consumption Institute (SCI) at the University of Manchester, research funding from the economics department at the University of Manchester, as well as the NERC Grant 'Predicting Secular Changes in Arsenic Hazard in Circum-Himalayan Groundwaters.' awarded to Polya (PI) van Dongen (CoI) and Ballentine (CoI), NE/J023833/1. The project was approved under UOM ethical application 13023.

Open Access This article is distributed under the terms of the Creative Commons Attribution 4.0 International License (http://creativecommons.org/licenses/by/4.0/), which permits unrestricted use, distribution, and reproduction in any medium, provided you give appropriate credit to the original author(s) and the source, provide a link to the Creative Commons license, and indicate if changes were made.

\section{References}

Abramson A, Becker N, Garb Y, Lazarovitch N (2011) Willingness to pay, borrow, and work for rural water service improvements in developing countries. Water Resour Res 47(11)

Ahlheim M, Frör O, Heinke A, Duc NM, Dinh PV (2010) Labour as a utility measure in contingent valuation studies: How good is it really? Technical report 
Arbiol J, Borja M, Yabe M, Nomura H, Gloriani N, Yoshida S (2013) Valuing human leptospirosis prevention using the opportunity cost of labor. Int J Environ Res Public Health 10(5):1845-1860

Asquith NM, Vargas MT, Wunder S (2008) Selling two environmental services: in-kind payments for bird habitat and watershed protection in Los Negros, Bolivia. Ecol Econ 65(4):675-684

Benner SG, Polizzotto ML, Kocar BD, Ganguly S, Phan K, Ouch K, Sampson M, Fendorf S (2008) Groundwater flow in an arsenic-contaminated aquifer, Mekong Delta, Cambodia. Appl Geochem 23(11):3072-3087

Berg M, Stengel C, Trang PTK, Viet PH, Sampson ML, Leng M, Samreth S, Fredericks D (2007) Magnitude of arsenic pollution in the Mekong and Red River Deltas-Cambodia and Vietnam. Sci Total Environ 372(2-3):413-425

Burton M, Rigby D (2009) Hurdle and latent class approaches to serial non-participation in choice models. Environ Resour Econ 42(2):211-226

Buschmann J, Berg M, Stengel C, Sampson ML (2007) Arsenic and manganese contamination of drinking water resources in Cambodia: coincidence of risk areas with low relief topography. Environ Sci Technol 41(7):2146-2152

Campbell D, Hensher DA, Scarpa R (2011) Non-attendance to attributes in environmental choice analysis: a latent class specification. J Environ Plan Manag 54:1061-1076

Casiwan-Launio C, Shinbo T, Morooka Y (2011) Island villagers' willingness to work or pay for sustainability of a marine fishery reserve: case of San Miguel Island, Philippines. Coast Manag 39(5):459-477

Cesario FJ (1976) Value of time in recreation benefit studies. Land Econ 52(1):32-41

DeShazo JR, Fermo G (2002) Designing choice sets for stated preference methods: the effects of complexity on choice consistency. J Environ Econ Manag 44(1):123-143

Echessah PN, Swallow BM, Kamara DW, Curry JJ (1997) Willingness to contribute labor and money to tsetse control: application of contingent valuation in Busia District, Kenya. World Dev 25(2):239-253

Eom YS, Larson D (2006) Valuing housework time from willingness to spend time and money for environmental quality improvements. Rev Econ Househ 4(3):205-227

Feldman PR, Rosenboom JW, Saray M, Navuth P, Samnang C, Iddings S (2007) Assessment of the chemical quality of drinking water in Cambodia. J Water Health 5(1):101-116

Fredericks D (2004) Situation analysis: arsenic contamination of groundwater in Cambodia. Technical report, Phnom Penh, Cambodia

Gault AG, Rowland HAL, Charnock JM, Wogelius RA, Gomez-Morilla I, Vong S, Leng M, Samreth S, Sampson ML, Polya DA (2008) Arsenic in hair and nails of individuals exposed to arsenic-rich groundwaters in Kandal province, Cambodia. Sci Total Environ 393(1):168-176

Hardner JJ (1996) Measuring the value of potable water in partially monetized rural economies. Water Resour Bull 32(6):1361-1366

Hensher D, Louviere J, Swait J (1999) Combining sources of preference data. J Econom 89(1-2):197-221

Hensher D, Shore N, Train K (2005) Households' willingness to pay for water service attributes. Environ Resour Econ 32(4):509-531

Hung LT, Loomis JB, Thinh VT (2007) Comparing money and labour payment in contingent valuation: the case of forest fire prevention in Vietnamese context. J Int Dev 19(2):173-185

IARC (2004) Some drinking-water disinfectants and contaminants, including arsenic. International Agency for Research on Cancer

Kamuanga M, Swallow BM, Sigue H, Bauer B (2001) Evaluating contingent and actual contributions to a local public good: Tsetse control in the Yale agro-pastoral zone, Burkina Faso. Ecol Econ 39(1):115-130

Kocar BD, Polizzotto ML, Benner SG, Ying SC, Ung M, Ouch K, Samreth S, Suy B, Phan K, Sampson M, Fendorf S (2008) Integrated biogeochemical and hydrologic processes driving arsenic release from shallow sediments to groundwaters of the Mekong delta. Appl Geochem 23(11):3059-3071

Kubota R, Kunito T, Agusa T, Fujihara J, Iwata H, Subramanian A, Tana TS, Tanabe S (2006) Urinary 8hydroxy-2-deoxyguanosine in inhabitants chronically exposed to arsenic in groundwater in Cambodia. J Environ Monit 8(2):293-299

Lado LR, Polya D, Winkel L, Berg M, Hegan A (2008) Modelling arsenic hazard in Cambodia: a geostatistical approach using ancillary data. Appl Geochem 23(11):3010-3018

Lagarde M (2013) Investigating attribute non-attendance and its consequences in choice experiments with latent class models. Health Econ 22(5):554-567

Mazumder DNG, Majumdar KK, Santra SC, Kol H, Vicheth C (2009) Occurrence of arsenicosis in a rural village of Cambodia. J Environ Sci Health Part A 44(5):480-487

NRC (1999) Arsenic in drinking water. National Academy Press, Washington

NRC (2001) Arsenic in drinking water 2001 update. National Academy Press, Washington

O'Garra T (2009) Bequest values for marine resources: How important for indigenous communities in lessdeveloped economies? Environ Resour Econ 44(2):179-202 
Polizzotto ML, Kocar BD, Benner SG, Sampson M, Fendorf S (2008) Near-surface wetland sediments as a source of arsenic release to ground water in Asia. Nature 454(7203):505-508

Polya DA, Gault AG, Bourne NJ, Lythgoe PR, Cooke DA (2003) Coupled HPLC-ICP-MS analysis indicates highly hazardous concentrations of dissolved arsenic species in Cambodian groundwaters. In: Holland G, Tanner SD (eds) Plasma source mass spectrometry: applications and emerging technologies, vol 288, Royal Society of Chemistry Special Publication, pp 127-140

Polya DA, Gault AG, Diebe N, Feldman P, Rosenboom JW, Gilligan E, Fredericks D, Milton AH, Sampson M, Rowland HAL, Lythgoe PR, Jones JC, Middleton C, Cooke DA (2005) Arsenic hazard in shallow Cambodian groundwaters. Mineral Mag 69(5):807-823

Polya DA, Berg M, Gault AG, Takahashi Y (2008) Arsenic in groundwaters of south-East Asia: with emphasis on Cambodia and Vietnam. Appl Geochem 23(11):2968-2976

Quicksall AN, Bostick BC, Sampson ML (2008) Linking organic matter deposition and iron mineral transformations to groundwater arsenic levels in the Mekong delta, Cambodia. Appl Geochem 23(11):3088-3098

Rai RK, Scarborough H (2013) Economic value of mitigation of plant invaders in a subsistence economy: incorporating labour as a mode of payment. Environ Dev Econ 18(02):225-244

Rai RK, Scarborough H (2014) Nonmarket valuation in developing countries: incorporating labour contributions in environmental benefits estimates. Aust J Agric Resour Econ 58:1-20

Rigby D, Alcon F, Burton M (2010) Supply uncertainty and the economic value of irrigation water. Eur Rev Agric Econ 37(1):97-117

Rose JM, Collins AT, Bliemer MC, Hensher DA (2009) Ngene 1.0 stated choice experiment design software, University of Sydney

Rowland HAL, Gault AG, Lythgoe P, Polya DA (2008) Geochemistry of aquifer sediments and arsenic-rich groundwaters from Kandal Province, Cambodia. Appl Geochem 23(11):3029-3046

Sampson ML, Bostock B, Chiew H, Hagan JM, Shantz A (2008) Arsenicosis in Cambodia: case studies and policy response. Appl Geochem 23(11):2977-2986

Scarpa R, Gilbride TJ, Campbell D, Hensher DA (2009) Modelling attribute non-attendance in choice experiments for rural landscape valuation. Eur Rev Agric Econ 36(2):151-174

Shyamsundar P, Kramer RA (1996) Tropical forest protection: an empirical analysis of the costs borne by local people. J Environ Econ Manag 31(2):129-144

Singh I, Squire L, Strauss J (1986) Agricultural household models: extensions, applications, and policy. The World Bank, The John Hopkins University Press, Baltimore

Skoufias E (1994) Using shadow wages to estimate labor supply of agricultural households. Am J Agric Econ 76(2):215-227

Sovann C, Polya D (2014) Improved groundwater geogenic arsenic hazard map for Cambodia. Environ Chem 11(5):595-607

Steinmaus CM, Ferreccio C, Romo JA, Yuan Y, Cortes S, Marshall G, Moore LE, Balmes JR, Liaw J, Golden $\mathrm{T}$ (2013) Drinking water arsenic in northern Chile: high cancer risks 40 years after exposure cessation. Cancer Epidemiol Biomarkers Prev 22(4):623-630

Sthiannopkao S, Kim KW, Sotham S, Choup S (2008) Arsenic and manganese in tube well waters of Prey Veng and Kandal provinces, Cambodia. Appl Geochem 23(5):1086-1093

Swallow BM, Woudyalew M (1994) Evaluating willingness to contribute to a local public good: application of contingent valuation to tsetse control in Ethiopia. Ecol Econ 11(2):153-161

Taylor JE, Adelman I (2003) Agricultural household models: genesis, evolution, and extensions. Rev Econ Househ 1:33-58

Tilahun M, Vranken L, Muys B, Deckers J, Gebregziabher K, Gebrehiwot K, Bauer H, Mathijs E (2013) Rural households' demand for frankincense forest censervation in Tigray. A contingent valuation analysis. Land Degradation \& Development, Ethiopia

Vondolia GK, Hk Eggert, Navrud S, Stage J (2014) What do respondents bring to contingent valuation? A comparison of monetary and labor payment vehicles. J Environ Econ Policy 3(3):253-267

Whittington D (2002) Improving the performance of contingent valuation studies in developing countries. Environ Resour Econ 22(1-2):323-367

Winkel L, Berg M, Amini M, Hug SJ, Johnson CA (2008) Predicting groundwater arsenic contamination in Southeast Asia from surface parameters. Nat Geosci 1(8):536-542 